\title{
Pitfalls from Psychology Science that Worsen with Practice
}

\author{
Donald A. Redelmeier, MD, FRCPC, MS (HSR), FACP $1,2,3,4$ and Lee D. Ross, PhD \\ 'Department of Medicine, University of Toronto, Toronto, Canada; ${ }^{2}$ Evaluative Clinical Sciences, Sunnybrook Health Sciences Centre, Sunnybrook \\ Research Institute, Toronto, Ontario, Canada; ${ }^{3}$ Institute for Clinical Evaluative Sciences in Ontario, Toronto, Canada; ${ }^{4}$ Centre for Leading Injury \\ Prevention Practice Education \& Research, Toronto, Canada; ${ }^{5}$ Department of Psychology, Stanford University, Stanford, CA, USA.
}

J Gen Intern Med 35(10):3050-2

DOI: $10.1007 / \mathrm{s} 11606-020-05864-5$

(c) Society of General Internal Medicine 2020

\section{INTRODUCTION}

Advances in science have made medical treatment increasingly successful. For example, the development of monoclonal antibody medications against Ebola infections is a meaningful advance for treating patients with a fatal disease. ${ }^{1}$ The literature is also littered with reversals characterized by early successes leading to hype and followed later by disappointment; for example, carotene for protecting against cancer, tight blood sugar control for preventing postoperative infections, and coronary stents for treating stable angina. ${ }^{2-4}$ In contrast to dynamic science literature, clinical practice changes slowly because early success is hypnotic and clinicians do not automatically absorb the potential gains in wisdom that years of experience can offer.

Cognitive psychology is the science that explores how people reason, formulate judgments, and make decisions (also related skills such as memory and language). The core theory is that errors can be systematic and do not necessarily disappear with experience. ${ }^{5,6}$ Indeed, learning from experience can be difficult and susceptible to many pitfalls. ${ }^{7}$ Insights and awareness from cognitive psychology, therefore, may make people less susceptible to pitfalls in reasoning and also help in drawing correct interferences from a range of outcomes observed by experience. ${ }^{8-10}$ Because changes in a patient's condition can result from factors other than the treatment provided, however, clinicians face a particularly difficult inferential task in learning from medical experience. ${ }^{11}$

A comprehensive review of the errors and biases relevant to medical judgment could include sources of overconfidence, wishful thinking, reliance on heuristics, loss aversion, motivational biases, and other failures beyond the scope of this article. ${ }^{12-14}$ Here, we limit the discussion to three specific pitfalls rooted in mistaken causal inferences that inhibit rather than promote learning from accumulating years of experience treating patients (Table 1). Each pitfall has counterintuitive features, is relevant to healthcare, reflects rigorous research,

Received October 24, 2019

Accepted April 16, 2020

Published online May 6, 2020 and is rarely discussed in standard medical training. The pitfalls are particularly germane in patient follow-up and address cases where the initial clinical outcome seems positive, negative, or ambiguous.

\section{Post Hoc Fallacy}

A core strength of medical practice is the trial-and-error strategy of initiating a treatment and assessing a patient's response. However, this strategy is subject to beguiling illusions because an observed change in the patient's health is not necessarily caused by the medical treatment. A classic fallacy is to mistakenly infer a causal link between two events that happen in sequence (formally termed the post hoc ergo propter hoc fallacy). Blatant examples of this fallacy appear in traditional folklore such as the superstitious belief that a rooster's call awakens the sun to rise. The same fallacy can cause patients with indolent papillary thyroid cancer to believe surgery was necessary (if follow-up shows no recurrence) or patients with back pain to believe acupuncture is effective (if acute treatment is followed by pain relief). ${ }^{15,} 16$

One demonstration of the post hoc fallacy tested parental views about sugar causing hyperactivity in children. ${ }^{17}$ In a randomized trial, half the parents were told their child had juice with sugar (intervention) whereas the other parents were told their child had juice with aspartame (controls). In a subsequent 7-point survey, intervention parents relative to control parents rated their child as more hyperactive despite all having had the same juice (4.37 vs 3.32, $p=0.006$ ). Sugar is often blamed for causing hyperactivity when a more common culprit is that it is often served at exciting events. ${ }^{18}$ In medicine, the same post hoc fallacy can mean a sore throat that resolves after antibiotics is credited to the antibiotics (thereby motivating excessive future use).

The voluminous literature on placebo effects illustrates how valid treatments also owe part of their effectiveness to the easing of anxiety, improved diet, reduced unhealthy habits, greater sleep, and other health choices by the patient (on top of psychosomatic effects and regression-to-the-mean). These positive changes are typically unmeasured yet frequently occur after a satisfying interaction with a clinician. For example, one trial suggested such placebo effects can exceed the direct benefit from medications to treat depression. ${ }^{19}$ More generally, a careful reading of scientific literature helps show the large before-and-after changes occurring in control patients and 
Table 1 Avoiding Pitfalls from Experience

\begin{tabular}{|c|c|c|c|c|}
\hline Pitfall & Definition & Example & Mitigation & Example \\
\hline $\begin{array}{l}\text { Post hoc } \\
\text { fallacy }\end{array}$ & $\begin{array}{l}\text { Assume a good outcome } \\
\text { was due to a good treatment }\end{array}$ & $\begin{array}{l}\text { "I started antibiotics, the patient } \\
\text { felt better, and this means my } \\
\text { treatment was right" }\end{array}$ & $\begin{array}{l}\text { Realize changes have } \\
\text { alternative } \\
\text { explanations }\end{array}$ & $\begin{array}{l}\text { "The improvement may be } \\
\text { unrelated to the antibiotics and } \\
\text { due to some other source" }\end{array}$ \\
\hline $\begin{array}{l}\text { Counterfactual } \\
\text { rationalization }\end{array}$ & $\begin{array}{l}\text { Accept a poor outcome by } \\
\text { thinking of a worse } \\
\text { alternative }\end{array}$ & $\begin{array}{l}\text { "This outcome is OK since my } \\
\text { patient would have done even } \\
\text { worse otherwise" }\end{array}$ & $\begin{array}{l}\text { Consider the full range } \\
\text { of other possible } \\
\text { outcomes }\end{array}$ & $\begin{array}{l}\text { "Let me consider whether a } \\
\text { different treatment could have } \\
\text { been better" }\end{array}$ \\
\hline $\begin{array}{l}\text { Likeability } \\
\text { bias }\end{array}$ & $\begin{array}{l}\text { Misinterpret ambiguous } \\
\text { results by seeking solace } \\
\text { from positive peers }\end{array}$ & $\begin{array}{l}\text { "My colleagues are respected } \\
\text { clinicians and they agreed with } \\
\text { my treatment" }\end{array}$ & $\begin{array}{l}\text { Appreciate that peers } \\
\text { engage in superficial } \\
\text { niceties }\end{array}$ & $\begin{array}{l}\text { "My colleagues tend to share my } \\
\text { views and are also motivated to } \\
\text { offer reassurance" }\end{array}$ \\
\hline
\end{tabular}

thereby can remind clinicians to rely less on simplistic explanations biased by the post hoc fallacy.

\section{Counterfactual Rationalization}

Clinicians may further develop faulty intuitions by neglecting the lessons from negative outcomes. A fundamental human temptation is to rationalize disappointing outcomes, particularly those that follow earlier successes with other patients. That is, a new failure can be too easily disregarded due to the legacy of past triumphs. Some of the rationalizations are benign or even constructive; for example, drawing comfort after a patient dies following elective hip surgery by knowing the procedure was justified by scientific evidence and that unfair blame is mostly rooted in hindsight bias. However, a particular type of rationalization can delay an experienced clinician from pursuing better options and stems from all the other patients that accumulate with time..$^{20}$

Social comparisons provide endless counterfactuals. One study, for example, rated the emotions of Olympic athletes. ${ }^{21}$ As expected, those winning gold were the happiest as gauged on a 10-point scale ( $0=$ "agony", $10=$ "ecstasy"). Surprisingly, those winning bronze were happier than those winning silver $(5.7$ vs $4.3, p<$ 0.001). A reason was bronze medalists easily imagined winning nothing whereas silver medalists thought of losing gold. Since downward comparisons are comforting and upward comparisons are dreary, the net effect was those with objectively worse outcomes felt emotionally happier. In medicine, such counterfactuals may cause cancer patients to feel fortunate despite chemotherapy toxicity by making selective comparisons with others in worse condition. ${ }^{22}$

Counterfactual rationalization is hard to suppress but the detrimental consequences in medical practice might be mitigated by encouraging clinicians to consider a range of realistic alternatives. Again, attention to the scientific literature on the possible results obtained with alternative treatments can be a good first step. Consultation with experienced colleagues who have witnessed a broad spectrum of outcomes can also be useful. In addition, the discussion of reasonable counterfactuals might help both in managing patient expectations and in bolstering the resiliency of the entire medical team after a complication. Many major achievements are not as great as they can feel initially and medical care requires modesty in the face of marginal progress. ${ }^{23}$

\section{Likeability Bias}

A further pitfall arises from clinical experience because a patient's outcome is frequently ambiguous, the yardsticks for a good result are uncertain, and colleagues help define what constitutes success. The benefits of such collegial friendships are substantial since colleagues have formal training, substantial experience, and professional authority. In contrast, a patient could be unreliable, disagreeable, or confused. ${ }^{24}$ In practice, this means a clinician naturally seeks selective feedback from a network of likeminded peers, can enjoy a significant emotional boost from collegial affirmations, and may too easily dismiss the views of a dissatisfied patient. Moreover, such feedback can be positively skewed due to shared groupthink, institutional alliances, or individual likeability. ${ }^{25}$

One frequently cited example of likeability bias involves the subjective grading of essays in an English class. ${ }^{26}$ By random assignment, the essay was accompanied by either an attractive or an unattractive photograph of the writer. All essays were then graded on a 9-point scale where 1 was "poor" and 9 was "excellent." As predicted, the essay was rated almost 2 points higher when accompanied by an attractive instead of an unattractive photograph $(6.0 \mathrm{vs} 4.3, p<0.01)$. In medicine, the same likeability bias may lead patients to place undue faith in a clinician who has nice bedside manner. Similarly, the likeability bias may lead responsible clinicians to place exaggerated faith on feedback from a likeable colleague who offers a positive opinion. ${ }^{27}$

Likeable colleagues can laud successes uncritically, share anecdotes about triumphs excessively, foster ingratiating rationalizations, and leave dubious explanations unquestioned. Friendly colleagues mostly provide friendly remarks since this is how they stay friends. Simple reassurances are also the easiest to provide in a direct personal relationship or a clinical conference. For daily practice, this pattern can discourage criticism, suppress dissent, and lead to a neglect of important alternatives. Similarly, clinicians may dismiss constructive criticism from those who lack a likeability halo solely because they offer a contrary view. ${ }^{28}$ As in personal life, clinicians should value professional friends who are willing to offer candid feedback. 


\section{CONCLUSION}

Experienced clinicians may be tempted to overlook pitfalls discovered by cognitive psychology science. ${ }^{29}$ Clinicians may emphasize - appropriately — the need for future research testing applications of debiasing strategies in daily clinical practice. ${ }^{30-}$ ${ }^{32}$ Naysayers might sometimes informally recognize such lapses in their colleagues but insist they are personally immune to such shortcomings. ${ }^{33}$ Ultimately, these viewpoints could reinforce bad habits that come with time and heighten resistance to medical advances based on scientific evidence. Recognition of pitfalls in reasoning when responding to positive, negative, or ambiguous patient outcomes, we suggest, might lead to a more effective and satisfying sustained practice of medicine.

Acknowledgments: We thank the following individuals for helpful comments on earlier drafts of this article: Alex Cressman, Edward Etchells, Michael Fralick, Neil Iscoe, Fizza Manzoor, Jonathan Milligan, Kelvin Ng, Camille Schull, Steven Shumak, and Gillian Spiegle.

Corresponding Author: Donald A. Redelmeier, MD, FRCPC, MS (HSR), FACP; Evaluative Clinical Sciences, Sunnybrook Health Sciences Centre Sunnybrook Research Institute, Toronto, Ontario, Canada (e-mail:dar@ices.on.ca).

Funding Information This project was supported by the Canada Research Chair in Medical Decision Sciences and the Canadian Institutes of Health Research.

\section{Compliance with Ethical Standards:}

Conducted at Sunnybrook Health Sciences Centre in Ontario, Canada.

Conflict of Interest: The authors declare that they do not have a conflict of interest.

Disclaimer: The funding organizations had no role in the design and conduct of the study; collection, management, analysis, and interpretation of the data; and preparation, review, or approval of the manuscript.

\section{REFERENCES}

1. Kupferschmidt K. Successful Ebola treatments promise to tame outbreak. Science 2019;365:628-9.

2. Hennekens CH, Buring JE, Manson JE, Stampfer M, Rosner B, Cook NR, Belanger C, LaMotte F, Gaziano JM, Ridker PM, Willett W, Peto R. Lack of effect of long-term supplementation with beta carotene on the incidence of malignant neoplasms and cardiovascular disease. N Engl J Med. 1996;334(18):1145-9.

3. Agus MS, Steil GM, Wypij D, Costello JM, Laussen PC, Langer M, Alexander JL, Scoppettuolo LA, Pigula FA, Charpie JR, Ohye RG, Gaies MG; SPECS Study Investigators. Tight glycemic control versus standard care after pediatric cardiac surgery. $N$ Engl J Med. 2012;367(13):1208-19.

4. Weintraub WS, Spertus JA, Kolm P, Maron DJ, Zhang Z, Jurkovitz C, Zhang W, Hartigan PM, Lewis C, Veledar E, Bowen J, Dunbar SB, Deaton C, Kaufman S, O'Rourke RA, Goeree R, Barnett PG, Teo KK, Boden WE; COURAGE Trial Research Group, Mancini GB. Effect of PCI on quality of life in patients with stable coronary disease. N Engl J Med. 2008;359(7):677-87.

5. Thaler RH, Sunstein CR. Nudge: Improving decisona about health, wealth, and happiness. New Haven: Yale University Press, 2008.

6. Shafir E. [ed]. The behavioral foundations of public policy. Princeton, New Jersey: Princeton University Press, 2013.
7. Nisbett RE, Ross L. Human inference: Strategies and shortcomings of social judgment. Englewood Cliffs, NJ: Prentice-Hall, 1980.

8. Graber ML, Kissam S, Payne VL, Meyer AN, Sorensen A, Lenfestey N, Tant E, Henriksen $\mathbf{K}$, Labresh $\mathbf{K}$, Singh $\mathbf{H}$. Cognitive interventions to reduce diagnostic error: a narrative review. BMJ Qual Saf. 2012;21(7):535-57.

9. Pope DG, Price J, Wolfers J. Awareness reduced racial bias. Management Science 2018;64(11):4967-5460.

10. Prakash S, Sladek RM, Schuwirth $\mathbf{L}$. Interventions to improve diagnostic decision making: A systematic review and meta-analysis on reflective strategies. Med Teach. 2019;41(5):517-524.

11. Kelley HH. The process of causal attribution. American Psychologist. 1973;28:107-128.

12. Redelmeier DA, Cialdini RB. Problems for clinical judgement: 5 . Principles of influence in medical practice. CMAJ. 2002;166(13):1680-4.

13. Redelmeier DA, Dickinson VM. Judging whether a patient is actually improving: more pitfalls from the science of human perception. J Gen Intern Med. 2012;27(9):1195-9.

14. Subramanian A, Connor DM, Berger G, Lessing JN, Mehta N, Manesh R, Kohlwes J. A Curriculum for Diagnostic Reasoning: JGIM's Exercises in Clinical Reasoning. J Gen Intern Med. 2019;34(3):344-345.

15. Welch HG, Doherty GM. Saving Thyroids - Overtreatment of Small Papillary Cancers. N Engl J Med. 2018;379(4):310-312.

16. Furlan AD, van Tulder MW, Cherkin DC, Tsukayama H, Lao L, Koes BW, Berman BM. Acupuncture and dry-needling for low back pain. Cochrane Database Syst Rev. 2005;(1):CD001351.

17. Hoover DW, Milich R. Effects of sugar ingestion expectancies on motherchild interactions. J Abn Child Psychol 1994:22:501-15.

18. Wolraich ML, Wilson DB, White JW. The effect of sugar on behavior or cognition in children. JAMA 1995;274:1617-21.

19. Gunduz-Bruce H, Silber C, Kaul I, Rothschild AJ, Riesenberg R, Sankoh AJ, Li H, Lasser R, Zorumski CF, Rubinow DR, Paul SM, Jonas J, Doherty JJ, Kanes SJ. Trial of SAGE-217 in Patients with Major Depressive Disorder. N Engl J Med. 2019;381(10):903-911.

20. Aspinwall LG, Taylor SE. Effects of social comparison direction, threat, and self-esteem on affect, self-evaluation, and expected success. J Pers Soc Psychol. 1993;64(5):708-22.

21. Medvec VH, Madey SF, Gilovich T. When less is more: Counterfactual thinking and satisfaction among Olympic medalists. J Pers Soc Psychol. 1995;69(4):603-610.

22. Diesen PS. "I Feel Lucky" - Gratitude among young adults with phenylketonuria (PKU). J Genet Couns. 2016;25(5):1002-9.

23. Davis DA, Mazmanian PE, Fordis M, Van Harrison R, Thorpe KE, Perrier L. Accuracy of physician self-assessment compared with observed measures of competence: a systematic review. JAMA. 2006;296(9): 1094-102.

24. Redelmeier DA, Dickinson VM. Determining whether a patient is feeling better: pitfalls from the science of human perception. J Gen Intern Med. 2011;26(8):900-6.

25. Turner ME, Pratkanis AR. Twenty-five years of groupthink theory and research: lessons from the evaluation of a theory. Organizational Behavior \& Human Decision Processes. 1998;73:105-115.

26. Landy D, Sigall H. Beauty is talent: Task evaluation as a function of the performer's physical attractiveness. Journal of Personality and Social Psychology. 1974;29(3):299-304.

27. Losin EAR, Anderson SR, Wager TD. Feelings of clinician-patient similarity and trust influence pain: Evidence from simulated clinical interactions. J Pain. 2017;18(7):787-799.

28. Redelmeier DA, Ross LD. Practicing medicine with colleagues: pitfalls from social psychology science. J Gen Intern Med. 2019;34(4):624-626.

29. Pronin E. How we see ourselves and how we see others. Science. 2008;320(5880):1177-80.

30. Rencic J, Trowbridge RL Jr., Fagan M, Szauter K, Durning S. Clinical Reasoning Education at US Medical Schools: Results from a National Survey of Internal Medicine Clerkship Directors. J Gen Intern Med. 2017;32(11):1242-1246.

31. Benartzi S, Beshears J, Milkman KL, Sunstein CR, Thaler RH, Shankar M, Tucker-Ray W, Congdon WJ, Galing S. Should governments invest more in nudging? Psychological science. 2017;28(8):1041-55.

32. Redelmeier DA, Ng K. Making the availability heuristic less available. BMJ Quality and Safety (in press).

33. Gilovich T, Ross L. The wisest one in the room: How you can benefit from social psychology's greatest insights. New York, NY: Simon \& Schuster, 2015.

Publisher's Note: Springer Nature remains neutral with regard to jurisdictional claims in published maps and institutional affiliations. 